\title{
LOCALIZED FORM OF LYMPHOMATOID PAPULOSIS, EVALUATING IN T-CELL LYMPHOMA - Case Report
}

\author{
S. Shtilionova ${ }^{1}$, P. Drumeva ${ }^{1}$, M. BalabanovaI ${ }^{2}$, I. Krasnaliev ${ }^{3}$ \\ 1) Department of dermatology and venereology, Medical University - Varna \\ 2) Department of dermatology and venereology, Medical University - Sofia \\ 3) Department of pathology, Medical University - Varna
}

\section{SUMMARY}

Lymphomatoid papulosis is presented by spontaneously regressing cutaneous infiltrates, that microscopically resemble a lymphomas and may evolve into Hodgkin or non- Hodgkin malignant lymphoma.

We present a case of Lymphomatoid papulosis in a 64 years old male, who complains from reddish non painful papules, localized symmetrically on the back and lateral zone of the legs.

The patient was treated for 10 weeks with low dose of methotrexat (15 mg per week) with good clinical result.

One year after treatment interruption the same patient had a similar clinical changes and hystochemical signs for development of T-cell lymphoma.

Key words: Lymphomatoid papulosis, T-cell lymphoma, hystopathology, immunohistochemistry

\section{CASE REPORT}

Lymphomatoid papulosis is a dermatological disorder firstly described by Dupont in 1965.It is presented by suddenly or spontaneously progressing cutaneous infiltrates, wich microscopically resemble a lymphoma. In some of the cases it can evoluate in Morbus Hodgkin or non-Hodgkin lymphoma.

We present a patient - male 64 years old.

The beginning of the disease starts about 1 year ago with appearance of non-painful, non - pruritic redish brown small nodules, covering symmetrically posterior and lateral areas of both thighs.
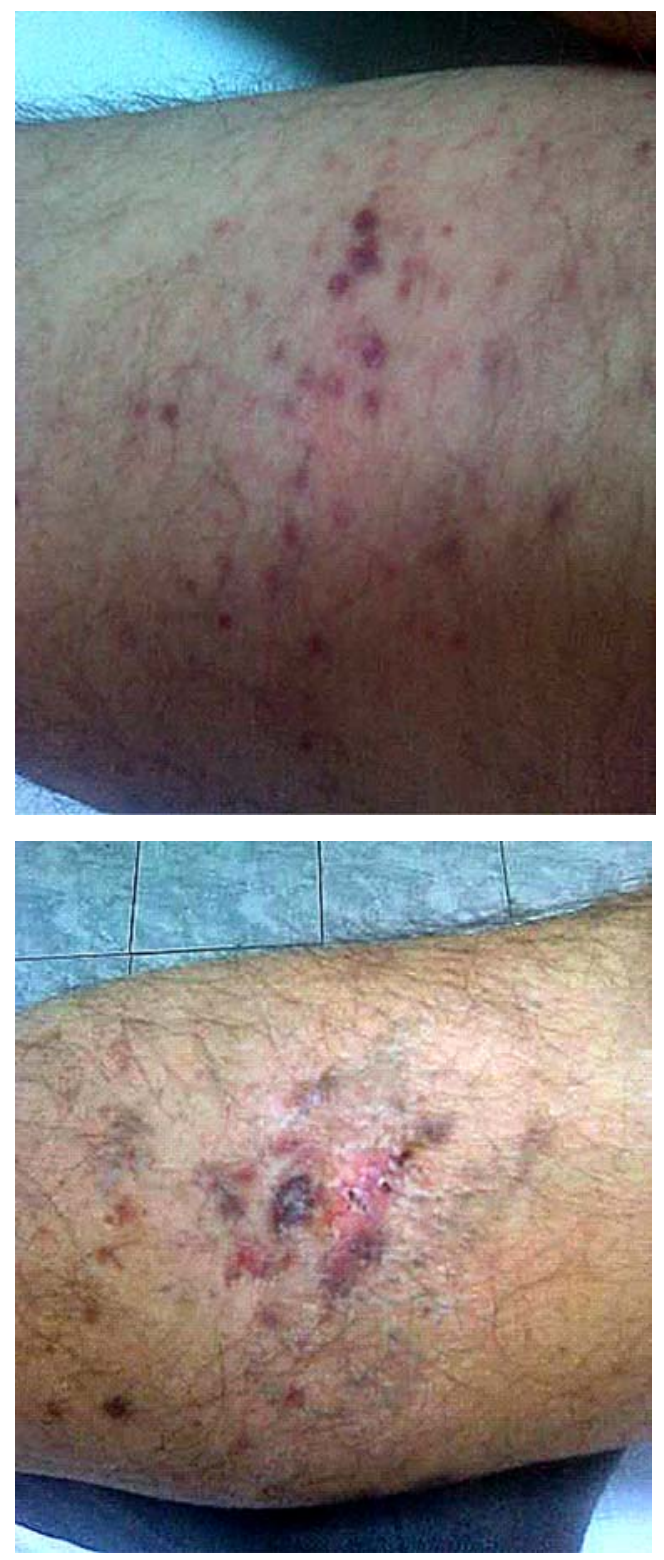
From the dermatological status:

The pathologic lesions affect posterior - lateral areas of both thighs. Morphologically they contain of grouped papules and nodules, reddish brown coloured and covered with gentle scales, predominantly at the peripheral zones. No enlarged lymphnodules are palpated.

From the laboratory analysis: $\mathrm{Hb} 100, \mathrm{Ht} 45$, Leuc $6,8, \mathrm{Ly}-36$, total protein 93 , creatinin 120 , urea 380

From the histopathological examination:

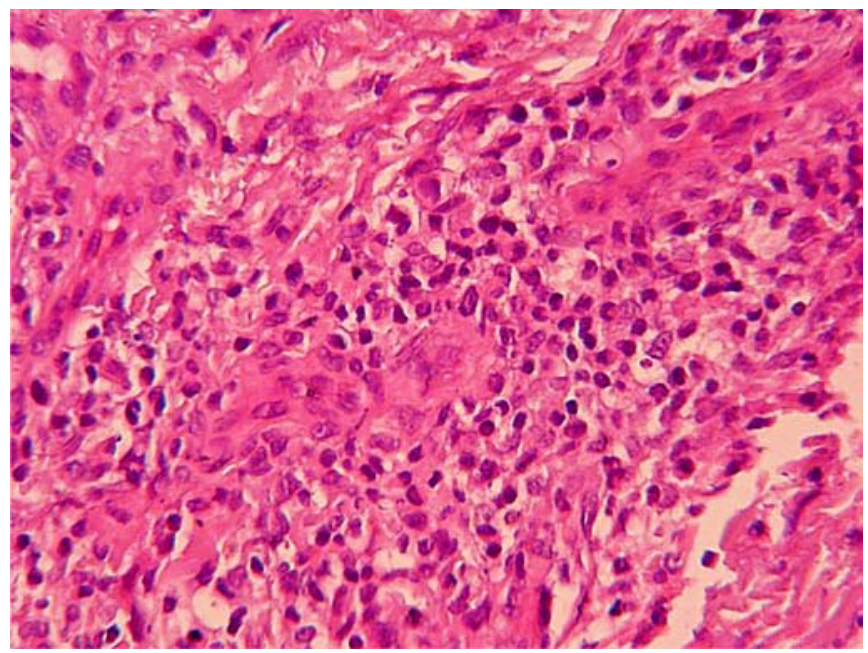

Skin biopsy - 2009 .

Cutis and subcutis with predominant perivascular as well periadnexial infiltration of large atypical lymphocytes, between witch a mixture of eosinophiles, neutrophiles and small lymphocytes is seen. There is no epidermotropism.

From the immunohistochemical examination:

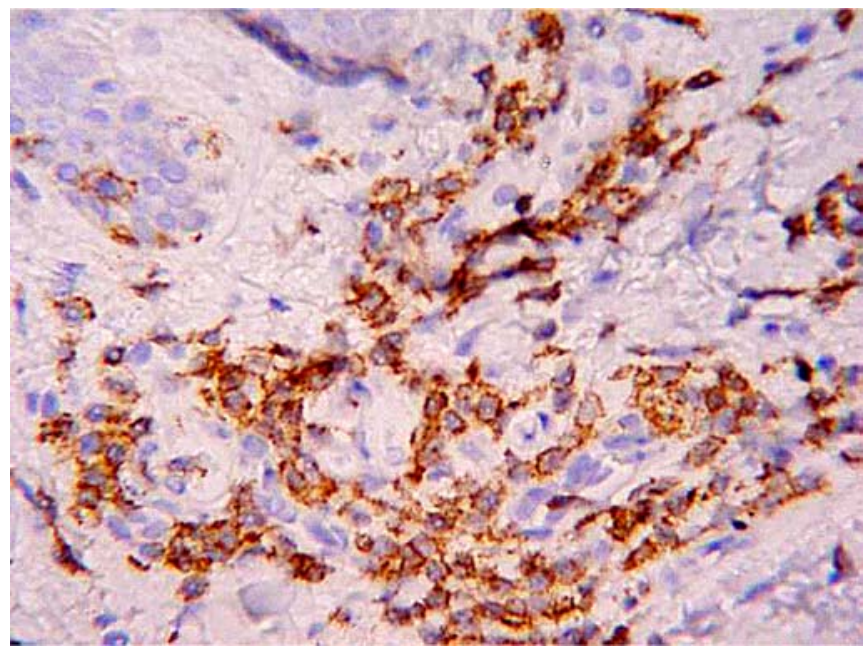

The infiltrate is CD 3 positive and CD 30 positive.

The treatment included low doses methotrexat $(15 \mathrm{mg} /$ weekly) for 10 weeks.
Good therapeutic result has been received showing resorbtion of all the pathological lesions, clearing the scales and forming postlesional hyperpigmented macules.

Three months after interrupting the treatment with methotrexad the clinical pattern of disease changed with appearance of new papulo-nodular lesions situated on the previous areas.

Second skin biopsy has been down. From the histopathological examination:

Skin biopsy 2010

Cutis and subcutis with crustformation, well distinguished perivascular infiltrate of atypic lymphocytes, among which - great number of large forms, small number of mixture of small lymphocytes and neutrophiles.

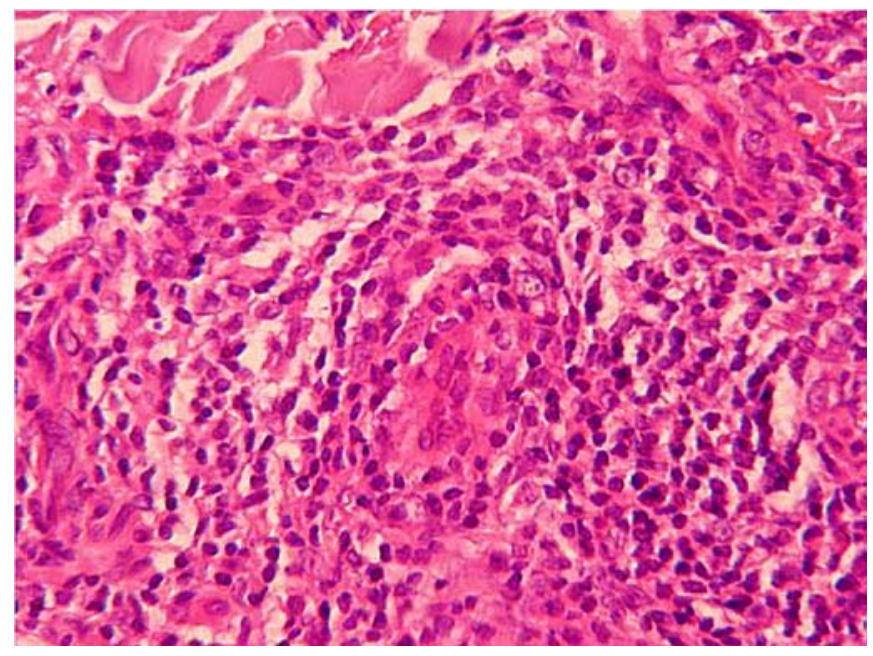

From the immunohystochemical examination: CD3, CD30, CD8 - negative, CD4 - diffuse, strongly positive.

The loss of expression of CD3 with CD4 positive can be interpreted as transition to T-cell lymphoma.

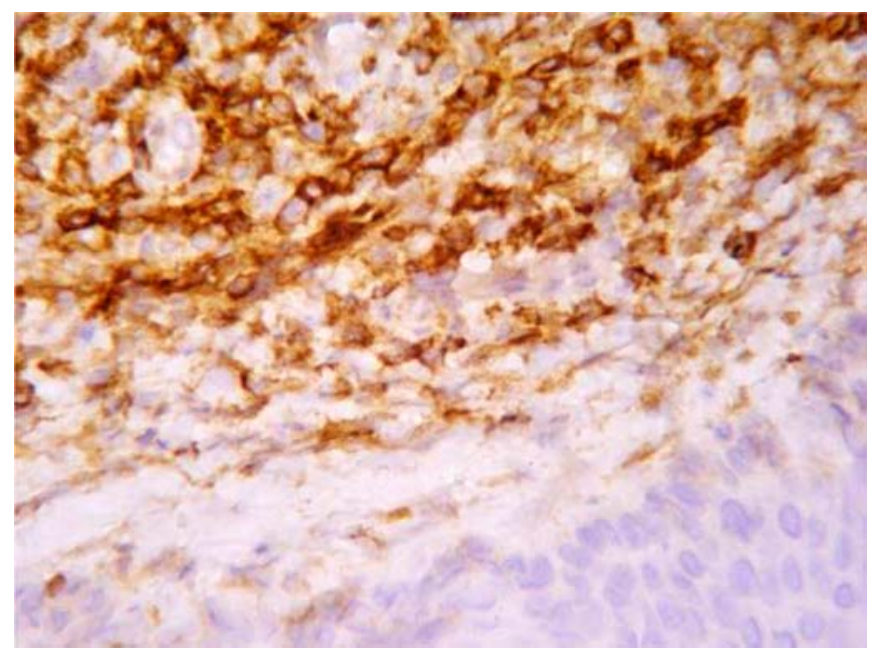




\section{DISCUSSION:}

The ethiology of Lymfomatoid papulosis is unclear and contradictory. Some authors have started that in 10-20\% of the cases, the patients could be evolve in Lymphoma or primary giant - cell anaplastic T-cell Lymphoma . In rare cases the disease could evolve in Mycosis fungoides $(1,2)$.

There are no objective criteria for the time, when the Lymphomatoid papulosis could evoluate in the mentioned above diseases, i. e to precede, attend, or to be there continuation. Even in the cases of regression of Lymphomatoid papulosis, the moleculary- biologic studies show criteria for transformation to T-cell Lymphoma $(2,3,4)$.

Clinical features of the Lymphomatoid papulosis ara presented by multiple asymmetric papules and nodules with slight peripheral desquamation, solitary haemorrhagia , crusts. In a few number of cases solitary tumour- like plaques are seen, but in other cases - a few number of reddish-brown papules, strongly separated from the surrounding tissue. They are situated on the upper and lower extremites, buttocks.All the lesions have recurrent evaluation in weeks or months, but with tendency to relapse . Lymphadenopathy is extraordinary seen.

Histopathological features of the disease are: primary non-epidermotropic mixedcell infiltrates, combined with eosinophiles, small lymphocytes, neutrophiles and histyocytes. In some of the cases the infiltrate is narrowbind shaped or nodular.

The large lymphocytes resemble the cells of the Anaplastic giant -cell Lymphoma -they are CD positive .They can be positive for CD2,3,4,5 as well as for proliferative marker K67(6) .
The laboratory analysis shows in rare cases lymphocytosis and hypregammaglobulinemia.

The course of the disease is chronic, as the lack of relapse more than 5 years means restoration to health. the clinical future that propose malignancy are ulceration, predominantly of the tumor like lesions and papulonecrotic changes, covering skin dermatoms(5).

We comment a patient with localized form of Lymphomatoid papulosis, in which the loss of expression of CD3, when having CD4 positive can be interpreted as transition to $\mathrm{T}$ - cell Lymphoma. Having in mind the possibility of transition of Lymphomatoid papulosis to malignant variant of lymphoma from great significance for the dermatologist is the clinical study of the patients as well as obligatory histopathological control of the eventual changes.

\section{CONCLUSIONS:}

1. Although the low percentage of the malignancy and relatively good prognosis for the course of Lymphomatoide papulosis, the patients suffering it, must be clinically and histopathologically controlled.

2. The localized form of Lymphomatoid papilosis is combatively rare, but brings the potential to evaluate in malignant form, as well as the standard disseminated variant.

3. The patients with Lyphomatoid papulosis, having tumor - like plaques with ulceration, as well as papulonecrotik lesions must be considered as criteria for eventual malignant transformation in variant Mycisis fungoides, Morbus Hodgkin or malignant non - Hodgkin Lymphoma.

\section{REFERENCES:}

1. Burg G, Kerl H, Schmoeckel C. Differentiation between malignant B-cell lymphomas and pseudolymphomas of the skin. J Dermatol Oncol 1984; 10: 271-275.

2. Burg G, Braun-Falco O. Cutaneous pseudolymphomas. In: Cutaneous lymphomas. Berlin: Springer-Verlag, 1983, 415-464.

3. Duncan SC, Evans HL, Winkelmann RK. Large cell lymphocytoma. Arch Dermatol 1980; 116: 1142-1146.
4. Dorfman RF, Warnke R. Lymphadenopathy simulating the malignant lymphomas. Hum Pathol 1974.

5. Englich JC, Smith NP, Wilson Jones E, Winkelmann RK. Large cell lymphocytoma [abstract]. J Cutan Pathol 1986; 13: 441.

6. Kerl H, Ackerman AB. Inflammatory diseases that simulate lymphomas: cutaneous pseudolymphomas. In:
Fitzpatrick TB, Eisen AZ, Wolff K, Freedberg IM, Austen KF (editors). Dermatology in general medicine, 4th ed. New York: McGrew-Hill, 1993, 1315 1327.

7. Landa N, Zelickson BD, Peters MS, et al. Cutaneous lymphoma versus pseudolymphoma: gene rearrangement studies of 21 cases with clinicopathologic correlation [Abstr.]. J Invest Dermatol

\author{
Address for correspondence: \\ Dr. Siana Shtilionova, \\ Department of dermatology and venereology, Medical University - Varna \\ 55, Marin Drinov str., 9000 Varna, Bulgaria \\ E-mail: shtilionova@abv.bg
}

